Proceedings of the 2018 International Scientific Conference 'Economic Sciences for Agribusiness and Rural Economy' No 1, Warsaw, 7-8 June 2018, pp. 140-145

\title{
SUSTAINABILITY IN URBAN VS. RURAL AREAS: A COMPARISON OF SUBJECTIVE AND OBJECTIVE INDICATORS ACROSS EUROPEAN COUNTRIES
}

\author{
Bruno Chiarini, Professor'; Antonella D’Agostino, Associate Professor ${ }^{2}$; \\ Elisabetta Marzano, Associate Professor ${ }^{3}$; Andrea Regoli, Associate Professor ${ }^{4}$
}

School of Economics and Law, University of Naples 'Parthenope'

\begin{abstract}
In this paper, starting from the approach described in Chiarini et al. (2017), who have provided a subjective measure of the environmental impact of cities (subjective EIC) at the country level, we extend the analysis comparing their indicator with the objective measure of the environmental impact of cities (objective EIC) suggested by Agenda 2030, namely mean levels of fine particulate matter (PM2.5 and PM10). The comparison between subjective and objective indicators of the EIC is a novelty in the panorama of the available studies, and provides useful results for policy analysis. In fact, the relative ranking of countries changes according to the metric adopted, and the analysis of association with macroeconomic indicators of development and growth reveal that subjective and objective EIC indicators might influence/be influenced by different macrofactors.
\end{abstract}

Keywords: perception of pollution, concentration of particulate matter, cross-country comparison JEL codes: Q5, O57, C25

\section{INTRODUCTION}

Several studies in the framework of quality of life, but also in the domains of poverty and deprivation, have found that subjective and objective indicators may tell a rather different story. Usually, objective indicators were found to be weak predictors of satisfaction in related life domains (Cummins, 2000). With reference to urban sustainability, we can expect that measures based on subjective perception of pollution and measures based on the actual level of pollutant concentration may give a different picture.

This paper investigates both types of information. Specifically, country rankings according to both measures are provided. The question we ask is twofold: (1) what explains the differences in the rankings; (2) is there a criterion to guide the researcher/policy maker to trust more one measure or the other one according to specific circumstances? The two questions are deeply linked to each other and raise the issue of

\footnotetext{
${ }^{1}$ Corresponding author: Via Generale Parisi 13, Naples, Italy, bruno.chiarini@uniparthenope.it, +39081 5474338

${ }^{2}$ Corresponding author: Via Generale Parisi 13, Naples, Italy, antonella.dagostino@uniparthenope.it, +39081547 4214

${ }^{3}$ Corresponding author: Via Generale Parisi 13, Naples, Italy, elisabetta.marzano@, uniparthenope.it, +3908154743 33

${ }^{4}$ Corresponding author: Via Generale Parisi 13, Naples, Italy, andrea.regoli@uniparthenope.it, +39081547 4256
} 
combining both indicators in order to increase their usefulness for policy makers.

\section{THEORETICAL BACKGROUND}

Urbanisation has been a fundamental feature of economic development, as documented in several papers (see, for instance, Galor, 2005; Chiarini and Marzano, 2014), albeit its role in fastening the improvement of economic conditions has been debated by recent literature (Jedwab and Vollrath, 2015). Moreover, the development of cities, and, especially in the less developed countries, megacities, is a serious concern for scholars investigating the issue of urban sustainability (Button, 2002). This is witnessed by the fact that in the 2030 Agenda for Sustainable Development (United Nations, 2015), the issue of sustainable cities is listed among the 17 sustainable development goals adopted in 2015 . With regard to goal 11, promoting sustainable cities, one of the targets to pursue by 2030 is listed as reducing 'the adverse per capita environmental impact of cities, by paying special attention to air quality and municipal and other waste management'. To this scope, one of the recommended indicators is the annual mean levels of fine particulate matter (e.g. PM2.5 and PM10) in cities.

The main idea of this paper is to compare objective indicators (such as environmental quantitative measures) and subjective indicators (such as individual perceptions). Subjective indicators of environmental discomfort deserve to be considered since individuals may differ not only in their exposure to environmental risk but also in their sensitivity to exposure (Schmit and Lorant, 2009). The analogies and discrepancies of both kinds of indicators could support decision making and policy analysis as regards to sustainability in urban areas vs. rural areas.

Studies that address the impact of pollution frequently resort to the use of both objective and subjective measures of environmental quality: the application fields range from epidemiology where the interest is in estimating the impact on health (Orru et al., 2018) to quality of life for the influence on life satisfaction (Liao, Shaw and Lin, 2015) to housing economics for the effect on housing prices (Berezan- sky, Portnov and Barzilai, 2010; Mínguez, Montero and Fernández-Avilés, 2013).

\section{MATERIALS AND METHODS}

\section{Subjective indicator: data and variables}

The subjective measure of the environmental impact of cities (Estimated Environmental Impact of Cities, EEIC) has been estimated on microdata from the 2013 wave of the European Union Statistics on Income and Living Conditions (EU-SILC; Eurostat, 2013).

The total final sample size consists of 184,876 households living in 26 European countries (23 EU countries plus Norway, Switzerland and Serbia): the within country sample size ranges from 3,630 households in Luxembourg to 15,703 in Italy.

The two main variables of interest are the indicator of environmental risk and the degree of urbanization, which represent the response variable and the key predictor in the estimated models, respectively. Differently from Chiarini et al. (2017), who measured environmental risk in terms of noise and air pollution, given the scope of our analysis, here we focus the attention only on self-reported problems of pollution where the household lives. This is coded as a dummy variable that equals 1 if the household perceived to be exposed to the risk of pollution. The degree of urbanization is a categorical regressor with three categories: large urban area, small urban area, rural area.

To derive the subjective indicator at the country level, for every country first we estimated a probit regression for the probability of perceiving pollution and then we computed the average marginal effect of the degree of urbanization on that probability. The average marginal effect has been computed by contrasting large urban area with rural area. Therefore, the indicator shows the difference in the predicted probability to report environmental risk when living in a large urban area and when living in a rural area. This difference is averaged across all households living in a country. More methodological details, which include also the selection of the control explanatory variables, can be found in Chiarini et al. (2017). 


\section{Objective indicator}

The objective indicator is based on the concentration of particulate matter (PM). It is well known that anthropogenic sources (such as traffic emissions or combustion activities) tend to produce more fine particulate (PM2.5, i.e. particles whose diameter is 2.5 micrometers at most) whereas natural sources are responsible for producing more PM10 particles (i.e. particles with a diameter of 10 micrometers at most).

The information about the population weighted annual means of PM2.5 and PM10 has been retrieved from the European Environmental Agency (EEA), with reference to year 2013. For every country, the objective indicator is derived as the PM2.5/PM10 ratio. Therefore, high values of this ratio signal that PM10 mainly consists of fine particles, that are likely to be found in urban areas, where usually a high density of human activities is found. This ratio is frequently used in spatial and/or temporal analyses (Munir, 2017; Talbi et al., 2018).

\section{RESULTS AND DISCUSSION}

The two indicators have been compared across countries by looking at the relative ranking of countries and by investigating the relationship between every indicator and country-level macroeconomic factors accounting for per capita GDP and growth rate.

By plotting the countries in a plane, with the $\mathrm{x}$ axis representing the PM ratio and the y axis representing the subjective indicator, and taking the medians of both indicators as reference lines (the red lines, Fig. 1), we see that the countries are scattered randomly in all four quadrants. The most industrialized European countries (Germany, Italy and France) combine above the median values of both indicators. The cleanest European countries (the Nordic countries) combine below the median values for both indicators. For other countries, high scores on one indicator are paired with relatively low scores on the other, and vice versa. Greece deserves to be mentioned as the country that ranks first in the subjective indicator and

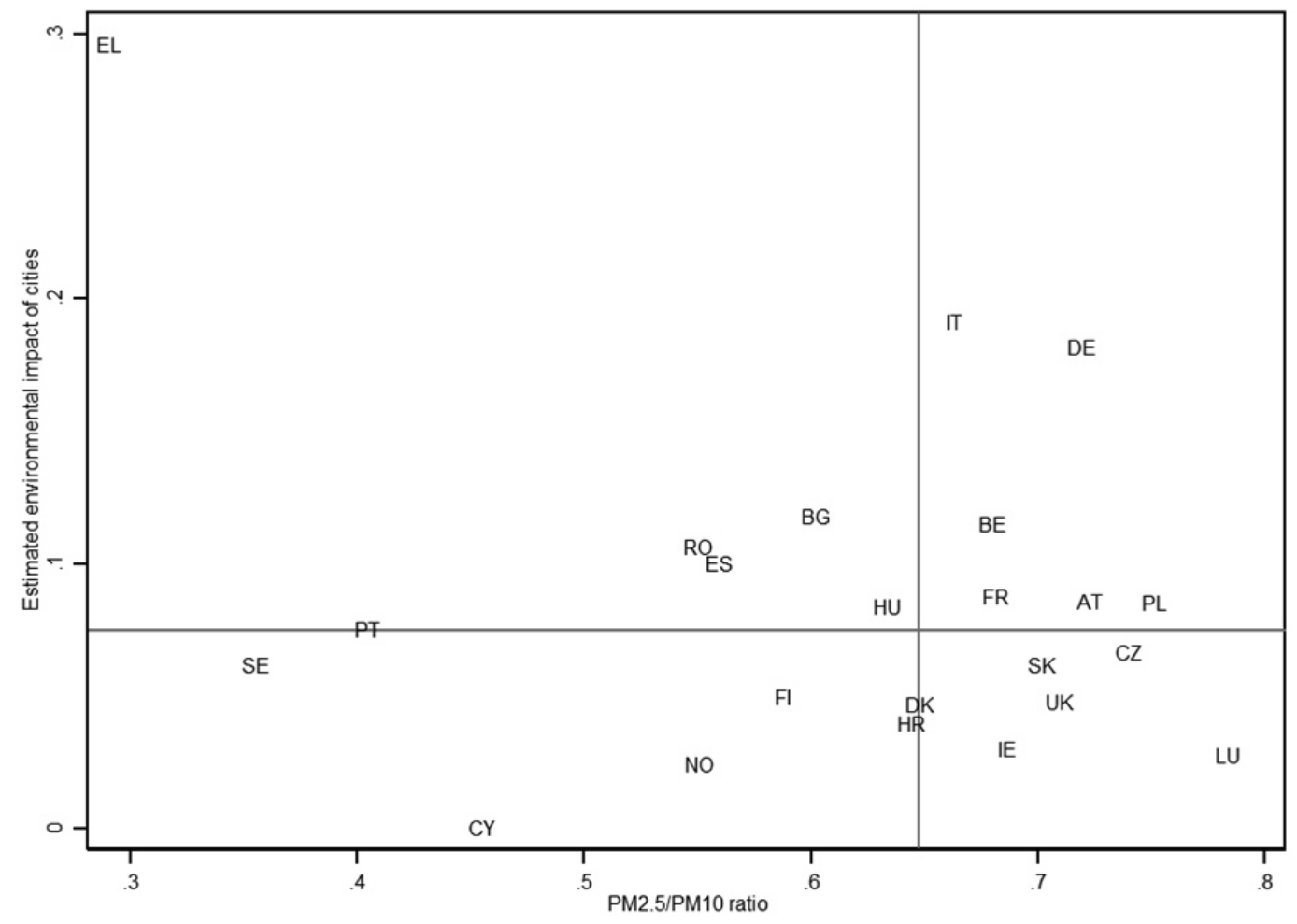

Figure 1. Subjective indicator (EEIC, y axis) vs. objective indicator (PM2.5/PM10 ratio, $\mathrm{x}$ axis) 


\section{a) Per capita GDP}

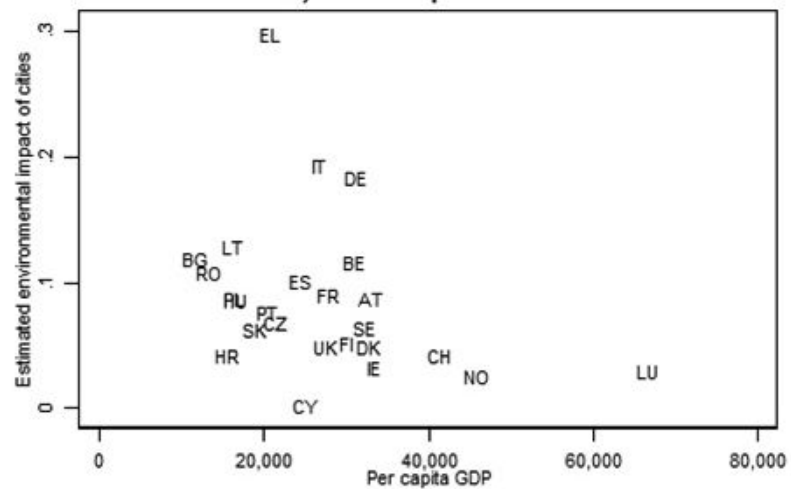

b) Growth rate in real GDP

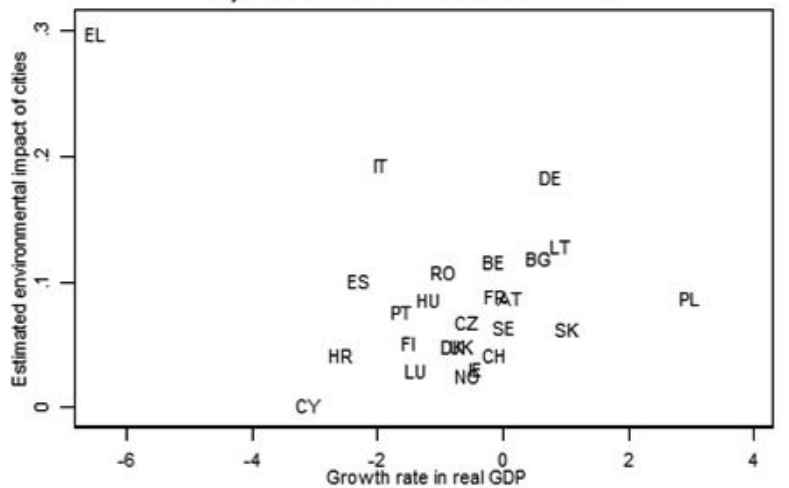

a) Per capita GDP

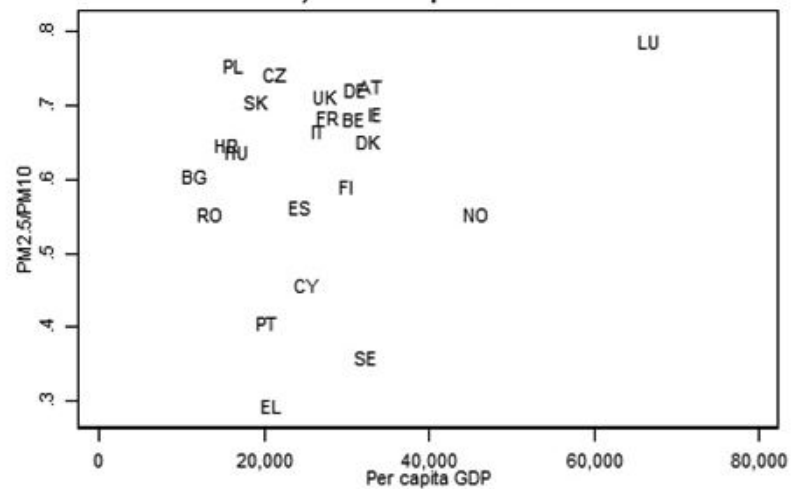

b) Growth rate in real GDP

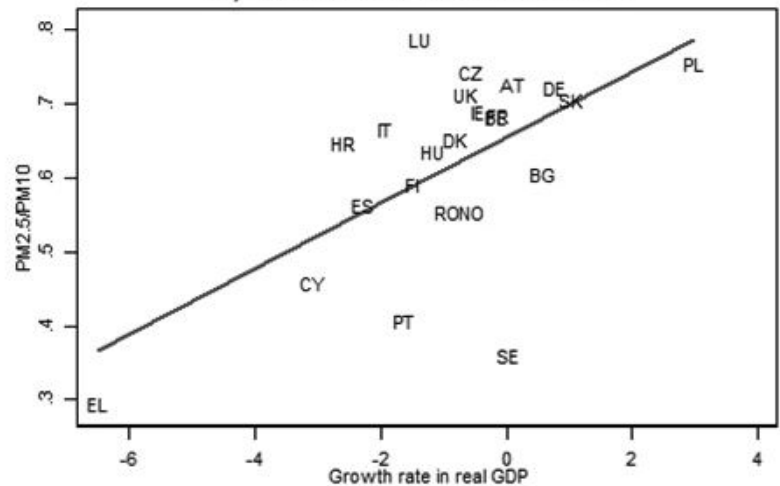

Figure 2. Subjective indicator (EEIC, left panel) and objective indicator (PM2.5/PM10 ratio, right panel) vs. per capita GDP and growth rate

last in the objective indicator. This unusual combination of values of both indicators qualifies Greece as an outlier, which should be investigated further.

In the whole, as a general result, the two rankings do not show any association (Spearman coefficient $-0.06)$.

The next issue we want to investigate is whether the two measures reflect different correlations with country level factors reflecting economic conditions and business cycle. To this end we plotted every indicator on per capita GDP and growth rate in real GDP. This information was extracted from the Eurostat database $\mathrm{e}^{5}$ and it is expressed as average during 2009-2012.
From Figure 2, no significant association seems to emerge between per capita GDP and growth rate with the subjective indicator (on the left) whereas there appears to be some evidence of a positive linear correlation between growth rate and the objective indicator (bottom right panel).

\section{CONCLUSIONS}

The subjective and objective measures of urban sustainability emerge as two different domains of the environmental impact of living in cities. Plausible explanations of the absence of correlation between the two indicators may concern: (i) issues of popula-

\footnotetext{
${ }^{5}$ http://ec.europa.eu/eurostat/data/database.
} 
tion density and/or concentration of polluting activities in urban areas; (ii) individual sensitivity to environmental issues, that is the threshold of subjective acceptance of pollution, that in turn can be affected by institutional features, environment-related legislation, cultural and psychological aspects.

For example, for countries where polluting industries are located away from residential areas, we can expect low levels of subjective indicator associated with even high values of objective indicator. This source of discrepancy may be mitigated in our case by the use of the PM2.5/PM10 ratio, which accounts for the share of emissions due to anthropogenic activities run in urban environments.

Furthermore, in countries where environment-related legislation is not very strict (where, for instance, citizens can circulate by using old cars), we expect larger objective EIC, and a sort of acquaintance with high levels of pollution, that could explain low perception. This observation has much to do with the explanation that reminds to cultural aspects. In countries where attention to environmental issues is widely present in the public opinion, it is expected that the threshold of acceptance of environmental pollution might be particularly low. Therefore, where the environmental culture is more lively, the presence of high levels of the subjective EIC might be contrasted with low measures of the objective measurement of the pollution.

These evidences suggest two orders of considerations. First, in the analysis of sustainability, a multidimensional approach which combines both subjective and objective information could prove to add useful insights to enrich the understanding. Second, while targeting policies aiming to pursue the goal of sustainable cities, it can be of help to expand the analysis beyond the realm of urban-mobility management practises. Specifically, policies targeted to limit the emissions should not disregard the business cycle dimension of air pollution, that is its positive association with the growth rate of GDP. Nevertheless, due to the uncorrelation between objective and subjective indicators, an improvement in the concentration of emissions does not automatically entail an improvement in the perception of urban sustainability.

\section{Acknowledgements}

The authors gratefully acknowledge the University of Naples Parthenope for funding provided under the competitive research programme 'Sostenibilità, esternalità e uso efficiente delle risorse ambientali', 2016-2018.

\section{REFERENCES}

1. Berezansky, B., Portnov, B.A., Barzilai, B. (2010). Objective vs. perceived air pollution as a factor of housing pricing: a case study of the greater Haifa metropolitan area. Journal of Real Estate Literature, 18 (1), pp. 99-124 .

2. Button, K. (2002). City management and urban environmental indicators. Ecological Economics, 40, pp. 217-233.

3. Chiarini, B., D’Agostino, A., Marzano, E., Regoli, A. (2017). Housing Environmental Risk in Urban Areas: Cross Country Comparison and Policy Implications. CESifo Working Paper 6822.

4. Chiarini, B., Marzano, E. (2014). Urbanization and growth: why did the splendor of the Italian cities in the sixteenth century not lead to transition? CESifo Working Paper 5038.

5. Cummins, R.A. (2000). Objective and subjective quality of life: an interactive model. Social Indicators Research, 52 (1), pp. 55-72.

6. Eurostat (2013). EU-SILC Description of Target Variables: Cross-sectional and Longitudinal. Publications Office of the European Union, Luxembourg.

7. Galor, O. (2005). Unified growth theory. In: Aghion, P., Durlauf, S. (eds.) Handbook of Economic Growth. North-Holland, Elsevier Science, Amsterdam.

8. Jedwab, R., Vollrath, D. (2015). Urbanization without growth in historical perspective, Explorations in Economic History, 58, C, pp. 1-21.

9. Liao, P., Shaw, D., Lin, Y. (2015). Environmental Quality and Life Satisfaction: Subjective Versus Objective Measures of Air Quality. Social Indicators Research, 124 (2), pp. 599-616.

10. Mínguez, R., Montero, J.M., Fernández-Avilés, G. (2013). Measuring the impact of pollution on property prices in Madrid: objective versus subjective pollution indicators in spatial models. Journal of Geographical Systems, 15 (2), pp. 169-191

11. Munir, S. (2017). Analysing Temporal Trends in the Ratios of PM2.5/PM10 in the UK. Aerosol and Air Quality Research, 17, pp. 34-48. 
12. Orru, K., Nordin, S., Harzia, H., Orru, H. (2018). The role of perceived air pollution and health risk perception in health symptoms and disease: a population-based study combined with modelled levels of PM10. International Archives of Occupational and Environmental Health, 91 (5), pp. 581-589.

13. Schmit, C., Lorant, V. (2009). Noise nuisance and health inequalities in Belgium: a population study. Archives of Public Health, 67 (2), pp. 52-61.
14. Talbi, A., Kerchich, Y., Kerbachi, R., Boughedaoui, M. (2018). Assessment of annual air pollution levels with PM1, PM2.5, PM10 and associated heavy metals in Algiers, Algeria. Environmental Pollution, 232, pp. 252$-263$.

15. United Nations (2015). Transforming our World: The 2030 Agenda for Sustainable Development

16. Zhang, J. (2002). Urbanisation, population transition, and growth. Oxford University Press, Oxford. 